\title{
Antibiotic resistance of Mycoplasma Synoviae strains isolated in China from 2016 to 2019
}

\author{
Xiaorong Zhang ${ }^{1 \dagger}$, Mengjiao Guo ${ }^{1 \dagger}$, Di Xie' ${ }^{1}$, Yang Chen ${ }^{1}$, Chengcheng Zhang ${ }^{1}$, Yongzhong Cao ${ }^{2}$ and \\ Yantao $\mathrm{Wu}^{1,2^{*}}$
}

\begin{abstract}
Background: In the past decade, Mycoplasma synoviae (M. synoviae) infection has become widely prevalent in China, has caused serious economic losses and has become one of the most important diseases in the chicken industry. Medication is a general approach for the control of $M$. synoviae infection, but antibiotics are sometimes ineffective in clinical practice. To investigate the sensitivity of $M$. synoviae to antimicrobials commonly used in the treatment of $M$. synoviae infection, the antibiotic susceptibility of 32 M. synoviae strains isolated from China from 2016 to 2019 were determined using the minimum inhibitory concentration (MIC) method.

Results: All isolates had low MIC values for the combination of lincomycin and spectinomycin, pleuromutilin, and macrolides. However, the M. synoviae isolates displayed variance in MICs for doxycycline hydrochloride with a range of 0.25 to $8 \mu \mathrm{g} / \mathrm{mL}$, and oxytetracycline hydrochloride with a range of 0.5 to $8 \mu \mathrm{g} / \mathrm{mL}$. Three and one M. synoviae isolates showed intermediate MIC values to doxycycline hydrochloride and oxytetracycline hydrochloride, respectively. High MIC values for enrofloxacin were detected in all isolates with MICs ranging from 4 to $32 \mu \mathrm{g} / \mathrm{mL}$. Furthermore, comparison of the parC QRDR identified a mutation at nucleotide position 254 (C254T) resulting in a Thr 85 lle amino acid change in all M. synoviae isolates and the reference strain ATCC 25204 being resistant to enrofloxacin. Moreover, mutations at Glu 804 Gly and Thr 686 Ala of gyrA QRDR were identified in all M. synoviae isolates and ATCC 25204. The mutation in the QRDR of the parE gene resulted in amino acid changes at positions 197 (Pro to Ser) in 27/32 M. synoviae isolates.
\end{abstract}

Conclusion: Three nonsynonymous mutations in gyrA and parE were first identified to be related to enrofloxacin resistance. Our results showed that $M$. synoviae resistance to enrofloxacin is widespread.

Keywords: Mycoplasma synoviae, Antimicrobial susceptibility, Minimum inhibitory concentrations, Resistance genes, Enrofloxacin resistance

\section{Background}

Mycoplasma synoviae (M. synoviae) is an important pathogen in chickens and turkeys worldwide that can cause acute or chronic infectious synovitis or air sacculitis [1,

\footnotetext{
*Correspondence: ytwu@yzu.edu.cn

${ }^{\dagger}$ Xiaorong Zhang and Mengjiao Guo contributed equally to this work.

1 Jiangsu Co-innovation Center for Prevention and Control of Important Animal Infectious Diseases and Zoonoses, College of Veterinary Medicine,

Yangzhou University, Yangzhou 225009, Jiangsu, China

Full list of author information is available at the end of the article
}

2]. In addition, $M$. synoviae infection can also result in a reduction in egg production and eggshell apex abnormalities or subclinical infections in commercial egg layers [3]. Importantly, M. synoviae infections can transmit horizontally and vertically. In recent years, $M$. synoviae infection has been widely prevalent in chicken flocks around the world. Previous study in the Netherlands showed that the prevalence of M. synoviae was $73.4 \%$ (127/173) in commercial layers during 2005 and 2006 [4]. In Portuguese, M. synoviae was found in $66.7 \%(24 / 36)$ of broiler breeder flocks between 2008 to and 2012 [5]. 
Other studies reported a prevalence of $15 \%$ in South America [6] and 27\% in Middle East [7]. In China, the incidence rate of chickens varies greatly in different provinces from 5.10 to $100 \%$, which has caused serious economic losses to the chicken industry [8]. Therefore, there has been a growing emphasis on the prevalence of $M$. synoviae, especially its subclinical infection.

The three general approaches for the control of $M$. synoviae infection are eradication strategies (maintaining flocks free of infection), vaccination and medication. Although eradication strategies and vaccination provide long-term solutions for the control of $M$. synoviae infection, medication can be very useful in preventing vertical transmission and clinical symptoms as well as economic losses [9]. However, antibiotic susceptibility should first be determined to maximize treatment efficacy. In most countries, excessive use of a range of antimicrobials in feed, on the one hand, prevents and treats disease and, on the other hand, improves growth performance. Antibiotic resistance is a global health threat, and the abuse of antimicrobials in animal production is the main contributing factor [10].

Mycoplasmas are readily resistant to $\beta$-lactam antibiotics and sulfones, but susceptible to other classes of antibiotics, including tetracyclines, macrolides, fluoroquinolones, and pleuromutilins [11-13]. Previous studies also demonstrated the efficacy of tiamulin fumarate (TIF) and the combination of lincomycin and spectinomycin (LS) against M. synoviae [14, 15]. However, increasing resistance of Mycoplasma against tetracyclines and quinolones has been reported [16, 17]. Quinolone resistance is related to point mutations in the quinolone resistancedetermining regions (QRDRs) of the A subunits of DNA gyrase and topoisomerase IV (parC and gyrA gene) or B subunits of DNA gyrase and topoisomerase IV ( $g y r B$ and parE gene) in M. synoviae [18].

As mentioned above, in recent years, $M$. synoviae infection has caused serious economic losses to the chicken industry. In addition to medication, vaccines also play an important role in controlling $M$. synoviae infection in China. Even when the oil emulsion vaccine is inoculated, it will be mixed with some anti-Mycoplasma antimicrobials (such as enrofloxacin and LS) for injection. This has become a common practice in many chicken farms during the brooding period and rearing period. These measures provide great selection pressure for the formation of drug resistance in M. synoviae. Our previous study demonstrated that $M$. synoviae strains isolated from China are relatively independent in terms of transmission and evolutionary relationships [19]. The antimicrobial medicines commonly used for the treatment of $M$. synoviae infection are sometimes ineffective in veterinary practice.
To screen the most effective antimicrobials, it is urgent to investigate the sensitivity of $M$. synoviae.

\section{Materials and methods \\ Strains}

The $M$. synoviae strains used in this study were isolated from China from 2016 to 2019 [19]. The isolates were cultured aerobically at $37^{\circ} \mathrm{C}$ in Mycoplasma broth $(\mathrm{pH}=7.8)$ with an MB base (OXOID Ltd., Hampshire, UK) containing $15 \%$ porcine serum, $3.3 \mathrm{~g} / \mathrm{L}$ glucose, $100 \mathrm{mg} / \mathrm{L}$ L-cysteine, $\quad 400 \mathrm{mg} / \mathrm{LL}$-arginine, $\quad 100 \mathrm{mg} / \mathrm{L}$ $\beta$-nicotinamide adenine dinucleotide trihydrate $(\beta-N A D)$, and $0.02 \%$ phenol red until the color of the culture medium changed from red to orange-yellow. These cultures were subsequently titrated in Mycoplasma broth medium to determine the number of color changing units (ccu). Then, sterile glycerol (5\%) was added to the cultures and stored at $-70^{\circ} \mathrm{C}$.

\section{Antimicrobials}

All strains were tested by the MIC method using the antimicrobials commonly used for $M$. synoviae treatment in farms as follows. LS, doxycycline hydrochloride (DO), valnemulin hydrochloride (VA), tylosin (TY), TIF, oxytetracycline hydrochloride (OT), enrofloxacin (ENR) and tilmicosin (TIL) were purchased from Solarbio Life Sciences (Beijing, China). The concentration of antibiotic solution was diluted to $128 \mu \mathrm{g} / \mathrm{mL}$. Then the solutions were sterilized with a $0.22-\mu \mathrm{m}$ membrane filter. The concentration range of antibiotics is shown in Table 3.

\section{Antimicrobial sensitivity test in vitro}

The liquid MIC test was carried out in 96-well microdilution plates as described in a previous study [20]. The M. synoviae culture was diluted in Mycoplasma broth medium in the range of $10^{3} \mathrm{ccu} / \mathrm{mL}$ and $10^{5} \mathrm{ccu} / \mathrm{mL}$. The concentration of antibiotic dilution was usually obtained by doubling dilutions with $100 \mu \mathrm{L}$ Mycoplasma broth medium $(\mathrm{pH}=7.8)$. After the dilution of antibiotic was completed, the $100 \mu \mathrm{L}$ dilution $M$. synoviae culture was inoculated into each well. M. synoviae culture and antibiotics were included in all tests as negative controls and antibiotic controls, respectively. Plates were incubated at $36 \pm 1{ }^{\circ} \mathrm{C}$. The lowest concentration of antibiotic to show a color change denoted MIC. The MIC was read when the phenol red indicator in the negative control had just turned orange-yellow. There is a lack of standardized methods and official breakpoints of susceptibility testing criteria for animal mycoplasmas in vitro. Thus, MIC values measured in this study were compared to previous studies. 
Quinolone resistance-determining regions and nucleotide sequence analysis

To elucidate the mechanism of acquired ENR resistance in $M$. synoviae isolates, the sequences $\operatorname{gyr} A, \operatorname{gyr} B$, parC, and parE of QRDRs were further analyzed. To amplify the QRDRs of $M$. synoviae isolates, the primers of $g y r A$, $\operatorname{gyr} B, \operatorname{par} C$, and $\operatorname{parE}$ (Table 1) were based on a previous study [17]. M. synoviae isolate cultures were harvested for DNA extraction using the TIANamp Bacteria DNA Kit (Transgen Biotech Co., Ltd., Beijing, China) according to the manufacturer's instructions. The sequences were aligned using Lasergene 7.1 software and blasted with those of reference M. synoviae strains MS-H (GenBank accession number: NZ_KP704286) and ATCC 25204 (GenBank accession number: NZ_CP011096). The nucleotide and amino acid positions were located based on the reference M. synoviae strain MS53 (GenBank accession number: AE017245).

\section{Results}

\section{MIC determinations}

In this study, $32 M$. synoviae isolates were tested for antibiotic susceptibility in vitro with 9 commonly used antimicrobials. The MICs of $32 \mathrm{M}$. synoviae isolates was shown in Table 2. All isolates had low MIC values for LS, with MICs ranging from 0.063 to $2 \mu \mathrm{g} / \mathrm{mL}$. An unimodal distribution of LS MIC value was observed. Thirty-one $M$. synoviae isolates showed MIC values for LS equal or lower to $1 \mu \mathrm{g} / \mathrm{mL}$ (MIC50 $=0.5 \mu \mathrm{g} / \mathrm{mL}$ ), while the rest were inhibited by a concentration of $2 \mu \mathrm{g} /$ $\mathrm{mL}$ (Table 3). For pleuromutilin, the M. synoviae isolates maintained low MIC values for both VA (MIC $<0.016 \sim 0.031 \mu \mathrm{g} / \mathrm{mL}$ ) and TIF (MIC $<0.016 \sim 0.063 \mu \mathrm{g} /$ $\mathrm{mL}$ ). Especially, most of the M. synoviae (31/32) had MIC values equal or lower than the lowest concentration of VA $(0.016 \mu \mathrm{g} / \mathrm{mL})$, only 1 isolate had a MIC to $0.031 \mu \mathrm{g} /$ $\mathrm{mL}$. The M. synoviae MICs for TY ranged from $<0.016$ to $1 \mu \mathrm{g} / \mathrm{mL}(\mathrm{MIC} 50=0.125 \mu \mathrm{g} / \mathrm{mL})$, which was the same as TIL (MIC50 $=0.063 \mu \mathrm{g} / \mathrm{mL}$ ), a macrolide antibiotic.

Table 1 Primer sequences used in this study

\begin{tabular}{lll}
\hline Primer name & Sequences $\left(\mathbf{5}^{\prime} \rightarrow \mathbf{3}^{\prime}\right)$ & Position $(\mathbf{b p})$ \\
\hline gyrA F & GAAGATCAGCCTGAATTAGTT & $58-78$ \\
gyrA R & GCCATTCTAGCTTCGGTATAA & $531-551$ \\
gyrB F & CAAGGTGAGAAATTCTCAAGA & $964-984$ \\
gyrB R & TGTGCTTCGTTATAAGCG & $1677-1694$ \\
parC F & CCAACCGTGCAATTCCTGAT & $95-114$ \\
parC R & TTATGCGGCGGCATTTCG & $546-563$ \\
parE F & GGCATATCGTCGAGGAAATAGC & $1034-1055$ \\
parE R & AGTGGTTTCCAAAGTTG & $1741-1758$ \\
\hline
\end{tabular}

However, the M. synoviae isolates displayed variance in MICs for tetracyclines, and intermediate MIC results were detected. MIC values for DO and OT, 3/32 and $1 / 32 M$. synoviae strains had the highest value at $8 \mu \mathrm{g} /$ $\mathrm{mL}$. The MIC50 and MIC90 values for DO were same as OT, being 2 and $4 \mu \mathrm{g} / \mathrm{mL}$ respectively (Table 3 ). Importantly, high MIC values for ENR were detected in all $M$. synoviae isolates with MICs ranging from 4 to $32 \mu \mathrm{g} /$ $\mathrm{mL}$. ENR MIC values were distributed unimodally and revealed that most of the $M$. synoviae (28/32) were inhibited by concentrations of $\geq 8 \mu \mathrm{g} / \mathrm{mL}$, with 12 isolates and 3 isolates showing MIC values of $16 \mu \mathrm{g} / \mathrm{mL}$ and $32 \mu \mathrm{g} / \mathrm{mL}$ respectively. MIC50 and MIC90 values of ENR were the highest, which were $8 \mu \mathrm{g} / \mathrm{mL}$ and $16 \mu \mathrm{g} / \mathrm{mL}$ respectively (Table 3).

\section{Molecular characterization of quinolone resistance-determining regions in $M$. synoviae isolates} To further investigate the mechanism of ENR resistance in M. synoviae, four resistance genes in the QRDRs of $32 \mathrm{M}$. synoviae isolates were amplified by PCR and sequenced. The reference strain ATCC 25204 is resistant to ENR and MS-H is susceptible to ENR. Four QRDR genes in the reference genome of $M$. synoviae strain MS53 were aligned with the sequences of ATCC 25204, MS-H and 32M. synoviae isolates. Several nonsynonymous mutations were found to be potentially resistance-related.

Sequence analysis of the gyrA QRDR showed that three SNPs in all M. synoviae isolates and ATCC 25204 resistant to ENR were identified. Mutations at nucleotide positions 2410 (A2410G) and 2411 (A2411G) resulted in Glu 804 Gly amino acid changes. A mutation at nucleotide position 2058 (A2058G) resulted in a Thr 686 Ala amino acid change. In the $g y r B$ gene, a SNP mutation was found at position 1250 (G1250A) and resulted in a Ser 417 Asn amino acid change in $11 / 32$ M. synoviae isolates with high MIC values for ENR. Comparison of the parC QRDR identified a mutation at nucleotide position 254 (C254T) resulting in a Thr 85 Ile amino acid change in all M. synoviae isolates and ATCC 25204. A mutation at nucleotide position 591 (C591T) of the parE gene resulting in a Pro 197 Ser amino acid change was also found in 27/32 M. synoviae isolates (Table 4).

\section{Discussion}

Antimicrobial resistance is a growing global concern for animals and humans. During the past decade, few studies have investigated the MICs of M. synoviae isolates in vitro. At present, the commonly used clinical antimicrobial medicines for the treatment of mycoplasma disease are macrolides (e.g., TY and TIL), pleuromutilins (e.g., valnemulin and TIF), tetracyclines (e.g., DO and 
Table 2 MICs of M. synoviae isolates

\begin{tabular}{|c|c|c|c|c|c|c|c|c|}
\hline \multirow[t]{2}{*}{ Isolates } & \multicolumn{8}{|c|}{ MIC ( $\mu \mathrm{g} / \mathrm{mL})$} \\
\hline & LS & VA & TIF & TY & TIL & DO & OT & ENR \\
\hline Ningxia/2019-1 & 0.5 & $<0.016$ & $<0.016$ & 0.063 & $<0.016$ & 4 & 1 & 4 \\
\hline Ningxia/2019-2 & 0.5 & $<0.016$ & $<0.016$ & 0.031 & $<0.016$ & 4 & 2 & 4 \\
\hline Hebei/2016-1 & 0.5 & $<0.016$ & 0.031 & 0.25 & 0.063 & 4 & 4 & 16 \\
\hline Hebei/2016-2 & 0.5 & $<0.016$ & $<0.016$ & 0.063 & 0.031 & 1 & 2 & 8 \\
\hline Hebei/2016-3 & 0.5 & $<0.016$ & $<0.016$ & 0.063 & 0.031 & 4 & 2 & 8 \\
\hline Shandong/2016-1 & 1 & $<0.016$ & 0.063 & 0.25 & 0.063 & 8 & 4 & 16 \\
\hline Shandong/2017-1 & 0.5 & $<0.016$ & $<0.016$ & $<0.016$ & $<0.016$ & 4 & 4 & 16 \\
\hline Shandong/2017-2 & 0.25 & $<0.016$ & 0.031 & 0.063 & 0.063 & 2 & 4 & 8 \\
\hline Shandong/2018-1 & 0.5 & $<0.016$ & $<0.016$ & 0.031 & 0.031 & 1 & 1 & 8 \\
\hline Hubei/2016-1 & 2 & $<0.016$ & $<0.016$ & 0.063 & 0.031 & 2 & 4 & 8 \\
\hline Jiangsu/2018-1 & 0.5 & $<0.016$ & 0.031 & 1 & 1 & 1 & 1 & 16 \\
\hline Jiangsu/2018-2 & 0.5 & $<0.016$ & 0.031 & 1 & 0.5 & 0.5 & 0.5 & 16 \\
\hline Jiangsu/2018-3 & 1 & $<0.016$ & 0.063 & 0.5 & 1 & 1 & 1 & 32 \\
\hline Jiangsu/2018-4 & 0.25 & $<0.016$ & $<0.016$ & 0.25 & 0.5 & 1 & 0.5 & 8 \\
\hline Jiangsu/2018-5 & 0.5 & $<0.016$ & $<0.016$ & $<0.016$ & 0.125 & 0.5 & 0.5 & 4 \\
\hline Jiangsu/2018-6 & 1 & $<0.016$ & 0.031 & 0.5 & 1 & 1 & 0.5 & 16 \\
\hline Anhui/2019-1 & 1 & $<0.016$ & 0.031 & 0.125 & 0.031 & 4 & 4 & 16 \\
\hline Anhui/2019-2 & 1 & $<0.016$ & 0.063 & 0.5 & 0.125 & 1 & 1 & 32 \\
\hline Jiangsu/2019-1 & 0.063 & $<0.016$ & $<0.016$ & $<0.016$ & $<0.016$ & 1 & 2 & 8 \\
\hline Shandong/2019-2 & 0.5 & $<0.016$ & $<0.016$ & 0.063 & 0.063 & 0.25 & 0.5 & 16 \\
\hline Shandong/2019-3 & 1 & $<0.016$ & 0.063 & 0.125 & 0.5 & 1 & 2 & 32 \\
\hline Shandong/2019-4 & 0.125 & $<0.016$ & $<0.016$ & $<0.016$ & $<0.016$ & 2 & 4 & 8 \\
\hline Ningxia/2019-3 & 0.125 & $<0.016$ & $<0.016$ & 0.125 & $<0.016$ & 2 & 2 & 8 \\
\hline Henan/2019-1 & 1 & $<0.016$ & 0.063 & 0.063 & 0.125 & 2 & 2 & 16 \\
\hline Jiangsu/2019-2 & 0.25 & $<0.016$ & $<0.016$ & 0.25 & 0.5 & 0.5 & 0.5 & 8 \\
\hline Jiangsu/2019-3 & 0.5 & $<0.016$ & 0.031 & 0.5 & 0.5 & 1 & 0.5 & 16 \\
\hline Ningxia/2019-4 & 0.5 & $<0.016$ & 0.031 & 0.25 & 0.063 & 8 & 2 & 8 \\
\hline Ningxia/2019-5 & 0.5 & $<0.016$ & 0.031 & 0.25 & 0.063 & 4 & 4 & 16 \\
\hline Heilongjiang/2019-1 & 0.5 & 0.031 & 0.031 & 0.125 & 0.063 & 4 & 2 & 8 \\
\hline Hebei/2018-1 & 0.125 & $<0.016$ & $<0.016$ & 0.031 & 0.031 & 2 & 2 & 8 \\
\hline Hebei/2018-2 & 1 & $<0.016$ & 0.063 & 0.125 & 0.031 & 8 & 8 & 16 \\
\hline Shandong/2019-5 & 0.125 & $<0.016$ & $<0.016$ & 0.063 & $<0.016$ & 2 & 1 & 4 \\
\hline
\end{tabular}

Table 3 Distribution of MIC values of the tested antimicrobials against the $32 \mathrm{M}$. synoviae isolates

\begin{tabular}{|c|c|c|c|c|c|c|c|c|c|c|c|c|c|}
\hline \multirow[t]{2}{*}{ Antimicrobials } & \multicolumn{13}{|c|}{ MIC Values $(\mu \mathrm{g} / \mathrm{mL})$} \\
\hline & 0.016 & 0.031 & 0.063 & 0.125 & 0.25 & 0.5 & 1 & 2 & 4 & 8 & 16 & 32 & 64 \\
\hline LS & & & 1 & 4 & 3 & $15^{50}$ & $8^{90}$ & 1 & & & & & \\
\hline VA & $31^{50-90}$ & 1 & & & & & & & & & & & \\
\hline TIF & $16^{50}$ & 10 & $6^{90}$ & & & & & & & & & & \\
\hline TY & 4 & 3 & 8 & $5^{50}$ & 6 & $4^{90}$ & 2 & & & & & & \\
\hline TIL & 7 & 7 & $7^{50}$ & 3 & & $5^{90}$ & 3 & & & & & & \\
\hline DO & & & & & 1 & 3 & 10 & $7^{50}$ & $8^{90}$ & 3 & & & \\
\hline OT & & & & & & 7 & 6 & $10^{50}$ & $8^{90}$ & 1 & & & \\
\hline ENR & & & & & & & & & 4 & $13^{50}$ & $12^{90}$ & 3 & \\
\hline
\end{tabular}

The MIC values are expressed in $\mu \mathrm{g} / \mathrm{mL}$. Superscript numbers indicate the MIC50 and MIC90 values 
Table 4 Molecular characterization of quinolone resistance-determining regions of $M$. synoviae isolates

\begin{tabular}{|c|c|c|c|c|c|c|c|c|c|c|c|c|}
\hline \multirow[t]{3}{*}{ Strains } & \multicolumn{6}{|l|}{ gyrA } & \multicolumn{2}{|l|}{ gyrB } & \multicolumn{2}{|l|}{ parC } & \multicolumn{2}{|l|}{ parE } \\
\hline & SNP & AA & SNP & AA & SNP & AA & SNP & AA & SNP & AA & SNP & AA \\
\hline & 2442 & 814 & $2410-2411$ & 804 & 2058 & 686 & 1250 & 417 & 254 & 85 & 591 & 197 \\
\hline MS-H & $C$ & Gln & AA & Glu & $A$ & Thr & G & Ser & C & Thr & C & Pro \\
\hline ATCC25204 & $C$ & Gln & GG & Gly & G & Ala & G & Ser & $\mathrm{T}$ & \|le & T & Ser \\
\hline Hebei/2016-1 & $C$ & Gln & GG & Gly & G & Ala & G & Ser & T & Ile & T & Ser \\
\hline Hebei/2016-2 & C & Gln & GG & Gly & G & Ala & G & Ser & T & lle & T & Ser \\
\hline Hebei/2016-3 & C & Gln & GG & Gly & G & Ala & G & Ser & T & lle & T & Ser \\
\hline Hebei/2018-1 & C & Gln & GG & Gly & G & Ala & G & Ser & $\mathrm{T}$ & lle & T & Ser \\
\hline Hebei/2018-2 & C & Gln & GG & Gly & G & Ala & G & Ser & $\mathrm{T}$ & Ile & $\mathrm{T}$ & Ser \\
\hline Jiangsu/2018-1 & C & Gln & GG & Gly & G & Ala & A & Asn & T & Ile & $\mathrm{T}$ & Ser \\
\hline Jiangsu/2018-2 & C & Gln & GG & Gly & G & Ala & A & Asn & $\mathrm{T}$ & Ile & T & Ser \\
\hline Jiangsu/2018-3 & C & Gln & GG & Gly & G & Ala & A & Asn & $\mathrm{T}$ & Ile & T & Ser \\
\hline Jiangsu/2018-4 & C & Gln & GG & Gly & G & Ala & A & Asn & $\mathrm{T}$ & lle & $\mathrm{T}$ & Ser \\
\hline Jiangsu/2018-5 & C & Gln & GG & Gly & G & Ala & A & Asn & $\mathrm{T}$ & Ile & $\mathrm{T}$ & Ser \\
\hline Jiangsu/2018-6 & C & Gln & GG & Gly & G & Ala & A & Asn & $\mathrm{T}$ & Ile & $\mathrm{T}$ & Ser \\
\hline Jiangsu/2019-1 & C & Gln & GG & Gly & G & Ala & G & Ser & $\mathrm{T}$ & Ile & $\mathrm{T}$ & Ser \\
\hline Jiangsu/2019-2 & C & Gln & GG & Gly & G & Ala & A & Asn & $\mathrm{T}$ & Ile & $\mathrm{T}$ & Ser \\
\hline Jiangsu/2019-3 & C & Gln & GG & Gly & G & Ala & A & Asn & $\mathrm{T}$ & Ile & $\mathrm{T}$ & Ser \\
\hline Ningxia/2019-1 & C & Gln & GG & Gly & G & Ala & G & Ser & $\mathrm{T}$ & lle & $\mathrm{T}$ & Ser \\
\hline Ningxia/2019-2 & C & Gln & GG & Gly & G & Ala & G & Ser & $\mathrm{T}$ & lle & $\mathrm{T}$ & Ser \\
\hline Ningxia/2019-3 & C & Gln & GG & Gly & G & Ala & G & Ser & $\mathrm{T}$ & lle & $\mathrm{T}$ & Ser \\
\hline Ningxia/2019-4 & C & Gln & GG & Gly & G & Ala & G & Ser & $\mathrm{T}$ & lle & $\mathrm{T}$ & Ser \\
\hline Ningxia/2019-5 & C & Gln & GG & Gly & G & Ala & G & Ser & $\mathrm{T}$ & lle & $\mathrm{T}$ & Ser \\
\hline Shandong/2016-1 & C & Gln & GG & Gly & G & Ala & G & Ser & $\mathrm{T}$ & lle & $\mathrm{T}$ & Ser \\
\hline Shandong/2017-1 & C & Gln & GG & Gly & G & Ala & G & Ser & $T$ & lle & $\mathrm{T}$ & Ser \\
\hline Shandong/2017-2 & C & Gln & GG & Gly & G & Ala & G & Ser & $\mathrm{T}$ & lle & C & Pro \\
\hline Shandong/2018-1 & A & Lys & GG & Gly & G & Ala & G & Ser & $\mathrm{T}$ & lle & $T$ & Ser \\
\hline Shandong/2019-2 & C & Gln & GG & Gly & G & Ala & A & Asn & $\mathrm{T}$ & lle & $\mathrm{T}$ & Ser \\
\hline Shandong/2019-3 & C & Gln & GG & Gly & G & Ala & G & Ser & $\mathrm{T}$ & lle & C & Pro \\
\hline Shandong/2019-4 & C & Gln & GG & Gly & G & Ala & G & Ser & $\mathrm{T}$ & lle & $\mathrm{T}$ & Ser \\
\hline Shandong/2019-5 & C & Gln & GG & Gly & G & Ala & A & Asn & $\mathrm{T}$ & lle & $\mathrm{T}$ & Ser \\
\hline Anhui/2019-1 & C & Gln & GG & Gly & G & Ala & G & Ser & $\mathrm{T}$ & lle & C & Pro \\
\hline Anhui/2019-2 & C & Gln & GG & Gly & G & Ala & A & Asn & $\mathrm{T}$ & Ile & T & Ser \\
\hline Henan/2019-1 & C & Gln & GG & Gly & G & Ala & G & Ser & $\mathrm{T}$ & Ile & C & Pro \\
\hline Hubei/2016-1 & C & Gln & GG & Gly & G & Ala & G & Ser & T & lle & C & Pro \\
\hline Heilongjiang/2019-1 & C & Gln & GG & Gly & G & Ala & G & Ser & T & lle & $\mathrm{T}$ & Ser \\
\hline
\end{tabular}

OT), fluoroquinolones (e.g., ENR), as well as LS. In this study, we investigated the antimicrobial susceptibility of 32 M. synoviae strains isolated from China from 2016 to 2019.

Our results showed that the MIC values of M. synoviae isolates were generally low for LS, pleuromutilin, and macrolides. Similar results were observed in a recent study in Asia, except for TIL [21]. When spectinomycin was applied in combination with lincomycin, it improved the efficacy of two antimicrobials against most M. synoviae [22]. In this study, $31 / 32$ isolates were sensitive to low concentrations of LS (MICs $0.063 \sim 1 \mu \mathrm{g} / \mathrm{mL}$ ). A previous study investigated the antibiotic susceptibility of $41 \mathrm{M}$. synoviae strains originating from Central and Eastern Europe between 2002 and 2016, including Hungary, Austria, the Czech Republic, Slovenia, Ukraine, Russia, and Serbia. Overall, similar low MIC values $(0.25 \sim 2 \mu \mathrm{g} /$ $\mathrm{mL}$ ) were detected for LS [13]. The macrolides showed good activity against $M$. synoviae strains worldwide, but higher MIC values $(>2 \mu \mathrm{g} / \mathrm{mL})$ were also identified in Europe [13, 23, 24]. In the current study, all isolates were sensitive to low concentrations of TY and TIL with MICs 
of only $2 / 32$ and $3 / 32$ isolates $=1 \mu \mathrm{g} / \mathrm{mL}$. In contrast, TIL MICs clearly showed a time-dependent gradual transition to high concentrations in $154 \mathrm{M}$. synoviae isolates from Italy collected from 2012 to 2017. Seven M. synoviae isolates showed an MIC $>32 \mu \mathrm{g} / \mathrm{mL}$ for TIL between 2013 and 2016 [25]. High MIC values were also detected in another study, which showed $25 / 87 \mathrm{M}$. synoviae strains with high MIC values $(>8 \mu \mathrm{g} / \mathrm{ml}$ for TIL and $/$ or $>1 \mu \mathrm{g} / \mathrm{ml}$ for $\mathrm{TY}$ and $/$ or $>0.5 \mu \mathrm{g} / \mathrm{ml}$ for tylvalosin) from 18 different countries from 1982 to 2019 [26]. As mentioned above, increased TIL MICs $\left(\geq 64 \mu \mathrm{g} / \mathrm{ml} \mathrm{MIC}_{90}\right.$ values) were also detected in M. synoviae isolates collected from China, India, Indonesia, Malaysia, the Philippines, the Republic of Korea, and Thailand [21]. Our results confirmed the high efficiency of TY and TIL against $M$. synoviae in China. Previous research has shown that pleuromutilins display high efficacy against avian mycoplasmas [27]. To date, the MIC values for TIF in the Europe mentioned above are relatively low $(0.004 \sim 2.5 \mu \mathrm{g} / \mathrm{mL})$. All M. synoviae isolates remained sensitive to TIF with MICs ranging from 0.12 to $2.5 \mu \mathrm{g} / \mathrm{mL}$ in South Africa between 2003 and 2015 [16]. The MIC values of VA were $\leq 0.039 \mu \mathrm{g} /$ $\mathrm{mL}$ in Central and Eastern Europe [26]. The M. synoviae isolates examined in this study showed high susceptibility to VA (MIC $<0.016 \sim 0.031 \mu \mathrm{g} / \mathrm{mL}$ ) and TIF (MIC $<0.016 \sim 0.063 \mu \mathrm{g} / \mathrm{mL})$. Especially, $31 \mathrm{M}$. synoviae isolates had MIC values equal or lower than the lowest concentration of VA $(0.016 \mu \mathrm{g} / \mathrm{mL})$. Therefore, pleuromutilins are supposed to be preferable in the treatment of M. synoviae infection.

For tetracyclines, $3 / 32$ of $M$. synoviae isolates showed intermediate MIC values for DO, and only one strain showed an intermediate MIC value for OT. The MIC50 and MIC90 values for DO were same as OT, being 2 and $4 \mu \mathrm{g} / \mathrm{mL}$ respectively. The finding of tetracycline resistance was not unexpected because of the long-term widespread use of tetracyclines in feed in China. Aureomycin, DO and OT are the most widely used antimicrobials. It can not only prevent bacterial infection but also improve the growth performance of animals. Our results indicated that long-term use of tetracycline antimicrobials can reduce the sensitivity of $M$. synoviae. Interestingly, even though the $M$. synoviae isolates did not have high MIC values of tetracyclines, our results do not align with previous studies in Europe, which showed that the MIC values of OT were higher than those of DO. For example, MIC values of OT and DO to M. synoviae were $0.031 \sim 32 \mu \mathrm{g} / \mathrm{mL}$ and $0.062 \sim 2 \mu \mathrm{g} / \mathrm{mL}$, respectively, from six European countries from 2014 to 2016 [24]. In another study, 84M. synoviae field strains were collected from 18 different countries from 2010 to 2019, and the majority of strains were from Hungary, Italy, the Netherlands, Israel, and Spain. The MIC values of OT and DO were $\leq 0.25 \sim 8 \mu \mathrm{g} / \mathrm{mL}$ and $\leq 0.039 \sim 1.25 \mu \mathrm{g} / \mathrm{mL}$, respectively [26]. The difference in MIC value may be due to the geographic area, density of poultry flocks, and different quantitative uses among countries. Since 2020, all forms of growth-promoting antimicrobials, except for traditional Chinese medicines have been forbidden to be used as feed additives in China. With the increase in the number of laws and regulations concerning the use of antimicrobials, we speculate that the resistance of $M$. synoviae to tetracyclines may be decreased in the future.

Previous studies showed that resistance to ENR increased rapidly [17, 28, 29]. In this study, high MIC values $(4 \sim 32 \mu \mathrm{g} / \mathrm{mL})$ for ENR were present in all $M$. synoviae isolates. The MIC50 and MIC90 values of ENR were the highest, with 12 isolates showing MIC values of $16 \mu \mathrm{g} / \mathrm{mL}, 3$ isolates showing MIC values of $32 \mu \mathrm{g} / \mathrm{mL}$. In Israel and Europe, decreased susceptibility to ENR was detected in $59 \%$ of M. synoviae field strains, with MICs ranging from 1 to $>16 \mu \mathrm{g} / \mathrm{mL}$ [17]. There is no standardized method for MIC testing in animal mycoplasma, but genetic mutations can determine the presence of antimicrobial resistance. To further investigate the mechanism of ENR resistance, $\operatorname{gyr} A, \operatorname{gyr} B, \operatorname{parC}$, and parE genes in the QRDRs of 32MS isolates were sequenced and analyzed. Topoisomerase IV ( $\operatorname{parC}$ ) is considered to be the primary target of ENR in M. synoviae, based on decreased susceptibility after experimental infection in vivo [18]. Amino acid positions 85-89 (80-84 according to Escherichia coli strain K-12 substrain MG1655) of parC were identified as hot spot regions that seem to have a principal role [26]. Amino acid substitutions at positions 80 and 84 of parC are known as important spots for ENR resistance in many bacteria, including mycoplasmas and may be alone or together with a mutation of gyrA [3033]. In addition, amino acid substitutions at positions 79 and 81 of parC were also identified in mycoplasma [17, 34]. In the current study, comparison of the parC QRDR identified a mutation at nucleotide position 254 (C254T) resulting in a Thr 85 Ile amino acid change in all $M$. synoviae isolates and ATCC 25204, which was similar to a previous study [26]. In the gyrB gene, a SNP mutation has been found at position 1250 (G1250A) and resulted in a Ser 417 Asn amino acid change in 11/32M. synoviae isolates with high MIC values to ENR, which has also been reported [17].

Comparison of the gyrA QRDR found the presence of different amino acid substitutions at positions 686, 804 and 814. Mutations at Glu 804 Gly and Thr 686 Ala were identified in all M. synoviae isolates and ATCC 25204. To our knowledge, these nonsynonymous mutations have not been reported in previous research. Our results revealed that there is a correlation between MIC values and amino acid mutations at positions 804 and 686 of 
the gyrA QRDR. Indeed, M. synoviae isolates containing these two amino acid substitutions had MICs ranging from 4 to $32 \mu \mathrm{g} / \mathrm{mL}$. These two amino acid mutations may together affect $M$. synoviae with decreased susceptibility to ENR. More strains with a broader spectrum of MICs should be identified to prove this conclusion, and the relevance of the mutations that occurred in $g y r A$ QRDR should be further investigated. The mutation in the QRDR of parE at positions 197 (Pro to Ser) in 27/32M. synoviae isolates has also not been reported. Amino acid substitution at position 420 of parE corresponds to residue 426 Asp of gyrB in E. coli, which is a multiple possible marker for quinolone resistance in many bacteria [35, 36]. The role of position 197 of parE in quinolone resistance needs to be further established.

In conclusion, $32 M$. synoviae isolates had low MIC values for the combination of lincomycin and spectinomycin, pleuromutilin and macrolides. However, 3/32 and $1 / 32 M$. synoviae isolates showed intermediate MIC values for DO and OT. High MIC values for ENR were detected in all isolates, with MICs ranging from 4 to $32 \mu \mathrm{g} / \mathrm{mL}$. Furthermore, mutations at Glu 804 Gly and Thr 686 Ala of $g y r A$ QRDR were identified in all $M$. synoviae isolates and ATCC 25204. The mutation in the QRDR of the parE gene resulted in amino acid changes at positions 197 (Pro to Ser) in 27/32 M. synoviae isolates. These nonsynonymous mutations were first identified to be related to ENR resistance.

\section{Acknowledgements}

Not applicable.

\section{Authors' contributions}

XRZ and MJG designed the study, performed most of the experiments. DX performed the molecular biology experiments. YC and YZC participated in the sequence alignment. MJG and DX wrote the manuscript. CCZ and YTW discussed the results and revised the manuscript. All authors read and approved the final manuscript.

\section{Funding}

This work was supported by the China Agriculture Research System of MOF and MARA (CARS-40), Modern Agriculture Development Project of Jiangsu Province (2020-SJ-003-YD16), and the Project Funded by the Priority Academic Program Development of Jiangsu Higher Education Institutions (PAPD).

\section{Availability of data and materials}

The datasets used and/or analysed during the current study available from the first author (E-mail: zxr@yzu.edu.cn) on reasonable request.

\section{Declarations}

Ethics approval and consent to participate

No animals or animal samples were used in the study. The ethics approval and consent to participate was not required.

\section{Consent for publication}

Not applicable.

\section{Competing interests}

The authors declare that the research was conducted in the absence of any commercial or financial relationships that could be construed as a potential conflict of interest.

\section{Author details}

1 Jiangsu Co-innovation Center for Prevention and Control of Important Animal Infectious Diseases and Zoonoses, College of Veterinary Medicine, Yangzhou University, Yangzhou 225009, Jiangsu, China. ${ }^{2}$ Joint International Research Laboratory of Agriculture \& Agri-Product Safety, Yangzhou University (JIRLAAPS), Yangzhou 225009, Jiangsu, China.

Received: 4 July 2021 Accepted: 9 December 2021

Published online: 03 January 2022

\section{References}

1. Vardaman TH, Reece FN, Deaton JW. Effect of Mycoplasma synoviae on broiler performance. Poult Sci. 1973;52(5):1909-12.

2. Lockaby S, Hoerr F, Lauerman L, Kleven S. Pathogenicity of Mycoplasma synoviae in broiler chickens. Vet Pathol. 1998;35(3):178-90.

3. Catania S, Gobbo F, Bilato D, Gagliazzo L, Moronato ML, Terregino C, et al. Two strains of Mycoplasma synoviae from chicken flocks on the same layer farm differ in their ability to produce eggshell apex abnormality. Vet Microbiol. 2016;193:60-6.

4. Feberwee A, de Vries TS, Landman WJ. Seroprevalence of Mycoplasma synoviae in Dutch commercial poultry farms. Avian Pathol. 2008;37(6):629-33.

5. Moreira FA, Cardoso L, Coelho AC. Epidemiological survey on Mycoplasma synoviae infection in Portuguese broiler breeder flocks. Vet Ital. 2015;51(2):93-8.

6. Buim MR, Mettifogo E, Timenetsky J, Kleven S, Ferreira A. Epidemiological survey on Mycoplasma gallisepticum and M. synoviae by multiplex PCR in commercial poultry. Pesquisa Veterinária Brasileira. 2009;29(7):552-6.

7. Amer M, Zohair G, El-Bayomi KM, Girh Z. Effect of Tilmicosin in control of mycoplasmosis in broiler chickens from infected breeders using ELISA test for evaluation. J Am Sci. 2012;8(3):696-700.

8. Sun S, Lin X, Chen F, Wang D, Lu J, Qin J, et al. Epidemiological investigation of Mycoplasma Synoviae in native chicken breeds in China. BMC Vet Res. 2017;13(1):115.

9. Kleven S. Control of avian mycoplasma infections in commercial poultry. Avian Dis. 2008;52(3):367-74.

10. Nhung N, Chansiripornchai N, Carrique-Mas J. Antimicrobial resistance in bacterial poultry pathogens: a review. Front Vet Sci. 2017;4:126.

11. Landman W, Mevius D, Veldman K, Feberwee A. In vitro antibiotic susceptibility of Dutch Mycoplasma synoviae field isolates originating from joint lesions and the respiratory tract of commercial poultry. Avian Pathol. 2008;37(4):415-20.

12. Gautier-Bouchardon A, Reinhardt A, Kobisch M, Kempf I. In vitro development of resistance to enrofloxacin, erythromycin, tylosin, tiamulin and oxytetracycline in Mycoplasma gallisepticum, Mycoplasma iowae and Mycoplasma synoviae. Vet Microbiol. 2002;88(1):47-58.

13. Kreizinger Z, Grózner D, Sulyok K, Nilsson K, HrivnákV, Benčina D, et al. Antibiotic susceptibility profiles of Mycoplasma synoviae strains originating from central and Eastern Europe. BMC Vet Res. 2017;13(1):342.

14. Hamdy A, Kleven S, McCune E. Efficacy of Linco-Spectin water medication on Mycoplasma synoviae Airsacculitis in broilers. Avian Dis. 1976;20(1):118-25.

15. Baughn C, Alpaugh W, Linkenheimer W, Maplesden D. Effect of tiamulin in chickens and turkeys infected experimentally with avian Mycoplasma. Avian Dis. 1978;22(4):620-6.

16. Beylefeld A, Wambulawaye P, Bwala D, Gouws J, Lukhele O, Wandrag D, et al. Evidence for Multidrug Resistance in Nonpathogenic Mycoplasma Species Isolated from South African Poultry. Appl Environ Microbiol. 2018;84:21.

17. Lysnyansky I, Gerchman I, Mikula I, Gobbo F, Catania S, Levisohn S. Molecular characterization of acquired enrofloxacin resistance in Mycoplasma synoviae field isolates. Antimicrob Agents Chemother. 2013;57(7):3072-7. 
18. Le Carrou J, Reinhardt AK, Kempf I, Gautier-Bouchardon AV. Persistence of Mycoplasma synoviae in hens after two enrofloxacin treatments and detection of mutations in the parC gene. Vet Res. 2006;37(1):145-54.

19. Zhang X, Chen Y, Xie D, Guo M, Ma S, Chen M, et al. Multi-locus sequence typing analysis of Mycoplasma synoviae isolates reveals unique sequence types in China. Vet Microbiol. 2021;259:109101.

20. Hannan P. Guidelines and recommendations for antimicrobial minimum inhibitory concentration (MIC) testing against veterinary mycoplasma species. Veterinary Res. 2000;31(4):373-95.

21. Morrow CJ, Kreizinger Z, Achari RR, Bekő K, Yvon C, Gyuranecz M. Antimicrobial susceptibility of pathogenic mycoplasmas in chickens in Asia. Vet Microbiol. 2020;250:108840.

22. Behbahan NGG, Asasi K, Afsharifar AR, Pourbakhsh SA. Susceptibilities of Mycoplasma gallisepticum and Mycoplasma synoviea isolates to antimicrobial agents in vitro. Int J Poult Sci. 2008;7(11):1058-64.

23. Hannan P, Windsor G, de Jong A, Schmeer N, Stegemann M. Comparative susceptibilities of various animal-pathogenic mycoplasmas to fluoroquinolones. Antimicrob Agents Chemother. 1997;41(9):2037-40.

24. de Jong A, Youala M, Klein U, El Garch F, Simjee S, Moyaert H, et al. Minimal inhibitory concentration of seven antimicrobials to Mycoplasma gallisepticum and Mycoplasma synoviae isolates from six European countries. Avian Pathol. 2021;50(2):161-73.

25. Catania S, Bottinelli M, Fincato A, Gastaldelli M, Barberio A, Gobbo F, et al. Evaluation of minimum inhibitory concentrations for 154 Mycoplasma synoviae isolates from Italy collected during 2012-2017. PLoS One. 2019;14(11):e0224903.

26. Bekő K, Kreizinger Z, Kovács ÁB, Sulyok KM, Marton S, Bányai K, et al. Mutations potentially associated with decreased susceptibility to fluoroquinolones, macrolides and lincomycin in Mycoplasma synoviae. Vet Microbiol. 2020;248:108818.

27. Li B, Shen J, Cao X, Wang Y, Dai L, Huang S, et al. Mutations in 23 S rRNA gene associated with decreased susceptibility to tiamulin and valnemulin in Mycoplasma gallisepticum. FEMS Microbiol Lett. 2010;308(2):144-9.

28. Gerchman I, Lysnyansky I, Perk S, Levisohn S. In vitro susceptibilities to fluoroquinolones in current and archived Mycoplasma gallisepticum and Mycoplasma synoviae isolates from meat-type turkeys. Vet Microbiol. 2008;131(3-4):266-76.

29. Gerchman I, Levisohn S, Mikula I, Manso-Silván L, Lysnyansky I. Characterization of in vivo-acquired resistance to macrolides of Mycoplasma gallisepticum strains isolated from poultry. Vet Res. 2011;42(1):90.

30. Lysnyansky I, Mikula I, Gerchman I, Levisohn S. Rapid detection of a point mutation in the parC gene associated with decreased susceptibility to fluoroquinolones in Mycoplasma bovis. Antimicrob Agents Chemother. 2009;53(11):4911-4

31. Lysnyansky I, Gerchman I, Perk S, Levisohn S. Molecular characterization and typing of enrofloxacin-resistant clinical isolates of Mycoplasma gallisepticum. Avian Dis. 2008;52(4):685-9.

32. Vicca J, Maes D, Stakenborg T, Butaye P, Minion F, Peeters J, et al. Resistance mechanism against fluoroquinolones in Mycoplasma hyopneumoniae field isolates. Microbial Drug Resistance (Larchmont, NY). 2007;13(3):166-70.

33. Hirose K, Kawasaki Y, Kotani K, Abiko K, Sato H. Characterization of a point mutation in the parC gene of Mycoplasma bovirhinis associated with fluoroquinolone resistance. J Vet Med B Infect Dis Vet Public Health 2004;51(4):169-75.

34. Bebear C, Renaudin J, Charron A, Renaudin H, de Barbeyrac B, Schaeverbeke T, et al. Mutations in the gyrA, parC, and parE genes associated with fluoroquinolone resistance in clinical isolates of Mycoplasma hominis. Antimicrob Agents Chemother. 1999;43(4):954-6.

35. Reinhardt A, Bébéar C, Kobisch M, Kempf I, Gautier-Bouchardon A. Characterization of mutations in DNA gyrase and topoisomerase IV involved in quinolone resistance of Mycoplasma gallisepticum mutants obtained in vitro. Antimicrob Agents Chemother. 2002;46(2):590-3.

36. Heddle J, Maxwell A. Quinolone-binding pocket of DNA gyrase: role of GyrB. Antimicrob Agents Chemother. 2002;46(6):1805-15.

\section{Publisher's Note}

Springer Nature remains neutral with regard to jurisdictional claims in published maps and institutional affiliations.

Ready to submit your research? Choose BMC and benefit from:

- fast, convenient online submission

- thorough peer review by experienced researchers in your field

- rapid publication on acceptance

- support for research data, including large and complex data types

- gold Open Access which fosters wider collaboration and increased citations

- maximum visibility for your research: over $100 \mathrm{M}$ website views per year

At BMC, research is always in progress.

Learn more biomedcentral.com/submissions 